\title{
The nonskeletal effects of vitamin D3 and the threshold limit associated with the risk of health complications
}

\author{
Mojto $\mathrm{V}^{1}$, Kolcunova $\mathrm{M}^{2}$, Rausova $\mathrm{Z}^{4}$, Chrenova $\mathrm{J}^{3}$, Dedik $\mathrm{L}^{4}$ \\ IIIrd Internal Clinic, Faculty of Medicine, Comenius University, Bratislava, Slovakia. \\ viliam.mojto@gmail.com
}

\section{ABSTRACT}

OBJECTIVE: To evaluate the threshold limit of vitamin D3 associated with the risk of nonskeletal health complications in humans.

BACKGROUND: Vitamin D3 deficiency is primary caused by a reduced sun exposure, consequent limiting of vitamin D3 production in the skin, and low intake of food with this vitamin.

METHODS: Ninety-two adults (25-95 years old) were admitted to III. Internal clinic or examined in outpatient department of The University hospital in Bratislava. Vitamin D3 levels were determined using electrochemical luminescence immunoassay. The least square method for the results processing was used.

RESULTS: Vitamin D3 level $16 \mathrm{ng} / \mathrm{ml}$ may be threshold limit for the risk of hypertension, ischaemic heart disease, renal insufficiency and diabetes mellitus. A higher occurrence of the observed diseases was in female and male patients with vitamin D3 levels $<16 \mathrm{ng} / \mathrm{ml}$. The highest increase of occurrence of diabetes mellitus in women for vitamin D3<16 ng/ml (160\%) compared to vitamin D3 $\geq 16 \mathrm{ng} / \mathrm{ml}(40 \%)$ was observed. Concerning the men, the highest increase refers to ischaemic heart disease $(67 \%)$.

CONCLUSION: The limit value of vitamin D3, $16 \mathrm{ng} / \mathrm{ml}$, confirmed the association between vitamin D3 insufficiency and the presence of hypertension, ischaemic heart disease, renal insufficiency and diabetes mellitus. Its relation to age, sex and other variables was detected (Tab. 1, Fig. 5, Ref. 27). Text in PDF www.elis.sk. KEY WORDS: diabetes mellitus, hypertension, threshold limit, Vitamin D3 level, insufficiency.

\section{Introduction}

Vitamin D3 constitutes an essential substance in the prevention of cardiovascular diseases, diabetes mellitus, renal diseases, cancers, auto-immune diseases, fracture prevention and other human affections (1-3). The effect of vitamin D mediated through the vitamin D receptor is more intensive to the metabolic functions, such as: the immune system, cell proliferation and differentiation, than from the viewpoint of the calcium metabolism control. Vitamin D has pleiotropic effects on immunity, endothelial and mucosal function and then vitamin D deficiency may worsen pre-existing immune and metabolic dysfunction. The higher risk associated with vitamin D deficiency was evident among individuals with a high blood pressure (4). The deficiency of vitamin D3 is primary caused by a reduced sun exposure, consequently limiting the vitamin D3 production in the skin and a low intake of food containing this vi-

${ }^{1}$ IIIrd Internal clinic, Faculty of Medicine, Comenius University, Bratislava, Slovakia, ${ }^{2}$ Ist Internal clinic, Faculty of Medicine, Comenius University, Bratislava, Slovakia, and ${ }^{3}$ Pharmacobiochemical Laboratory of IIIrd Internal Clinic, Faculty of Medicine, Comenius University, Bratislava, Slovakia, and ${ }^{4}$ Institute of Automation, Measurement and Applied Informatics, Faculty of Mechanical Engineering, Slovak University of Technology, Bratislava, Slovakia

Address for correspondence:V. Mojto, IIIrd Internal clinic, Faculty of Medicine, Comenius University, Limbova 5, SK-833 05 Bratislava, Slovakia. Phone: +421.2 .59542349$

Acknowledgements: This study was supported by the Scientific Grant Agency VEGA no. 1/0338/08, VEGA no. 1/0604/15, and the Philanthropic fund of Studio 727 Bratislava. tamin. The Health Professional Follow-Up Study (5) found that men with a low level of vitamin D3 were twice as likely to have a heart attack as men with an adequate level of vitamin D3. Low vitamin D3 levels are associated with a higher risk of heart failure, sudden cardiac death, stroke, overall cardiovascular disease, and cardiovascular death (6-9). How exactly might vitamin D3 help to prevent the heart disease? There's the evidence that vitamin D3 plays a role in controlling blood pressure and preventing artery damage, and this may explain these findings (10). Type 1 diabetes mellitus varies with geography - a child in Finland is about 400 times more likely to develop this disease than a child in Venezuela (11). Evidence that vitamin D3 may play a role in the prevention of type 1 diabetes comes from a 30-year study that followed Finnish children, where children, who regularly received vitamin D3 supplements during infancy had a nearly 90 percent lower risk of developing type 1 diabetes than those, who did not receive supplements (12). Other European case-control studies also suggested that vitamin D3 might help to protect against type 1 diabetes (13). In the kidney, vitamin D3 may be important for maintenance of podocyte health, prevention of epithelial-to-mesenchyme transformation, suppression of renin gene expression and inflammation (14). Prevalence of the vitamin D deficiency is $30-60 \%$ of US and European population (4). The deficiency of vitamin D was considered one of the probable reasons of high mortality in Scotland between 1950 and 1980 (15). Worldwide, the vitamin D3 deficiencies can be found in the people of all continents, within all ethnic groups and/or ages. Some surveys suggest that almost a half of the world's population 


\section{3-136}

has inadequate blood levels of vitamin D3 (16-18). World defined prevalent limit value of vitamin D3 for assessment of influence of vitamin D3 concentration on diagnosis is $30 \mathrm{ng} / \mathrm{ml}$. However, this limit is different in individual human populations of the world. Consequently, our work was aimed to detect the critical threshold for chosen age- and sex-heterogeneous group of patients, and to evaluate the association between vitamin D3 insufficiency and the presence of hypertension, ischaemic heart disease, renal insufficiency and diabetes mellitus in relation to age and other variables.

\section{Materials and methods}

\section{Patients and methods}

A group of 92 adult patients ( 25 - 95 years old) was admitted to IIIrd Internal Clinic, Faculty of Medicine, Comenius University or examined in outpatient department of Derer's University Hospital in Bratislava. The study was approved by the ethics committee and was conducted in accordance with the principles of the Declaration of Helsinki. The analyses of plasma blood samples were performed from April 2009 to October 2009. Vitamin D3 levels were determined using electrochemical luminescence immunoassay. Serum 25-hydroxycalciferolvitamin D levels $\leq 30 \mathrm{ng} / \mathrm{ml}$ were characterized as vitamin D3 insufficiency. The results were processed by the least squares method.

\section{Results}

Figure 1 showed the whole distribution of the tested group of patients according to the observed diagnoses.

Based on the least squares method, the relationship between the plasma blood vitamin D3 concentration and the patients age and/or the seasons of the year was analyzed by a regression line in the form:

vitamin D3 (age) = 19.57-0.061' age (Fig. 2) and/or regression parabola in the form:

vitamin D3 (month) $=-20.40+9.30^{\prime}$ month $-0.56^{\prime}$ month $^{2}$ (Fig. 3), respectively.

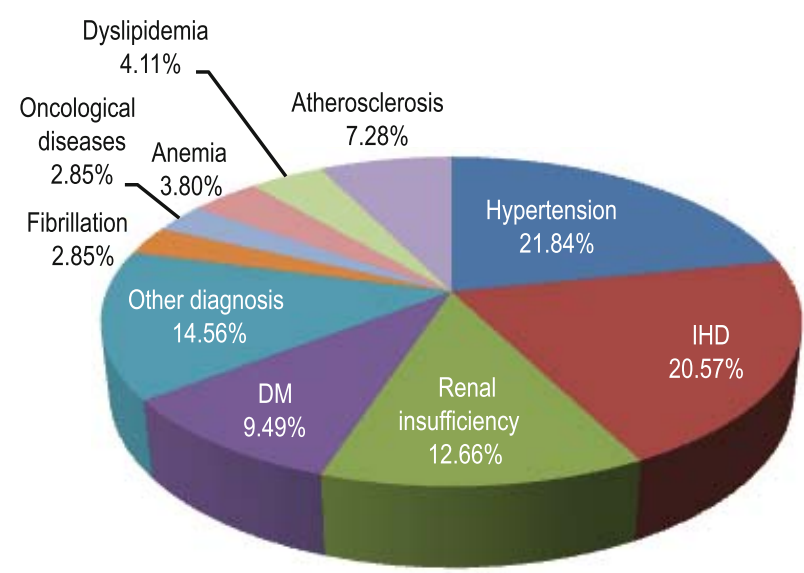

Fig. 1.Percentage distribution of patients according to the observed diagnoses. Other diagnoses: Glucose tolerance impairment, Hepatopathy, Hypothyreosis, Thrombocytopenia, Cardiomyopathy, Metabolic syndrome, Chronic venous insufficiency, Cirrhosis, Coeliac disease, Emphysema, Asthma. IHD - Ischaemic heart disease.

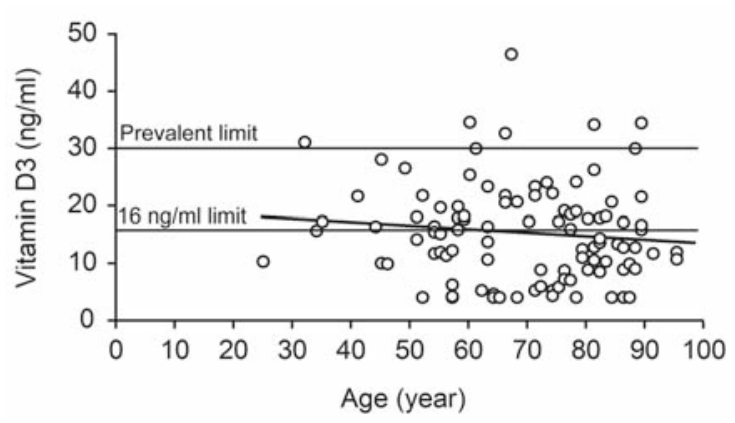

Fig. 2.Dependence of vitamin D3 occurrence on the patient age.Circles - measured vitamin D3 concentrations, solid line - regression line.

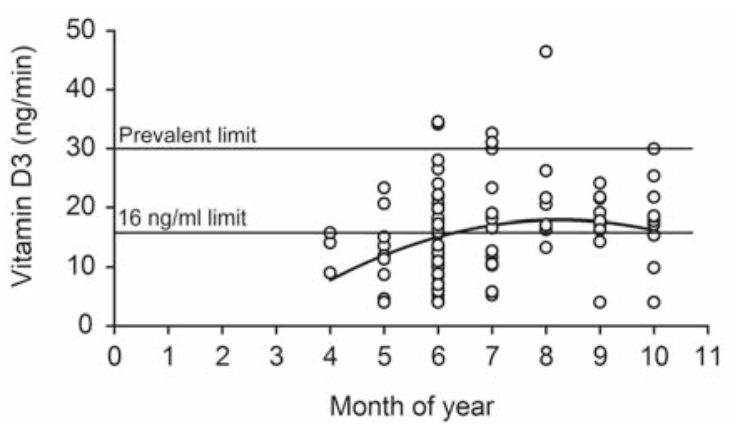

Fig. 3.Dependence of vitamin D3 occurrence on the season.Circles measured vitamin D3 concentrations, solid line - regression parabola.

According to world considered prevalent limit $30 \mathrm{ng} / \mathrm{ml}$, Figs 2 and 3 showed that $5 \%$ of the whole patients group had an adequate vitamin D3 blood concentration situated above this limit line, independently of the age or the season. However, $95 \%$ of the patients with vitamin D3 blood concentration situated on and below the prevalent limit line demonstrated the insufficiency of this vitamin. Regarding the tested patients and diseases, the results of the regression analyses indicated $16 \mathrm{ng} / \mathrm{ml}$ as a suitable limit value for assessment of vitamin D3 concentration influence on tested human diagnosis. Overall, $75 \%$ of adults from tested patients group had hypertension, $71 \%$ had ischaemic heart disease, $43 \%$ had renal insufficiency, $33 \%$ had diabetes mellitus, $95 \%$ of patients had vitamin D3 insufficiency. There was a higher occurrence of diseases in adults whose vitamin D3 levels were $<16 \mathrm{ng} / \mathrm{mL}$ while both sexes were equally affected. Observed threshold limit is sustained also by comparison between the measured vitamin D3 concentration and the patient age (Fig. 2) or the season (Fig. 3).

Figures 4 and 5 show detected a higher occurrence of diseases in female and male patients, respectively, with vitamin D3 levels $<16 \mathrm{ng} / \mathrm{ml}$.

Table 1 describes that the highest increase of occurrence of diabetes mellitus in women for vitamin D3 $<16 \mathrm{ng} / \mathrm{ml}(160 \%)$ towards vitamin D3 $\geq 16 \mathrm{ng} / \mathrm{ml}$ (40\%) was observed.

Concerning the men, the highest increase refers to ischaemic heart disease IHD (67\%), where both sexes were equally affected. Consequently, $16 \mathrm{ng} / \mathrm{ml}$ of vitamin D3, as the threshold limit value for the risk of hypertension, ischaemic heart disease, renal insufficiency and diabetes mellitus, was observed. 
Tab. 1. Relationship between increase of diagnoses numbers (D) for vitamin D3 $<16 \mathrm{ng} / \mathrm{ml}$ towards diagnoses numbers for vitamin D3 $\geq$ $16 \mathrm{ng} / \mathrm{ml}$ in individual groups of patients.

\begin{tabular}{lcccc}
\hline Groups & $\begin{array}{c}\Delta \text { Hypertension } \\
(\%)\end{array}$ & $\begin{array}{c}\Delta \text { IHD } \\
(\%)\end{array}$ & $\begin{array}{c}\Delta \text { Renal } \\
\text { insufficiency }(\%)\end{array}$ & $\begin{array}{c}\Delta \text { Diabetes } \\
\text { mellitus }(\%)\end{array}$ \\
\hline Women & 19 & 54 & 44 & 160 \\
Men & 62 & 67 & 57 & 40 \\
\hline
\end{tabular}

\section{Discussion}

According to the obtained results, the association between vitamin D3 insufficiency and the presence of hypertension, ischaemic heart disease, renal insufficiency and diabetes mellitus, even after adjustment for age, sex and other variables, was observed. The heart like skeletal muscle contains the receptors for vitamin D. Therefore, the relationship between the deficiency of vitamin $\mathrm{D}$ and the heart diseases is evident. Despite the fact that world defined prevalent limit of vitamin D3 is $30 \mathrm{ng} / \mathrm{ml}$, many scientific studies consider a different threshold for assessment of influence of vitamin D3 concentration in human diagnosis. Schwalfenberg et al (2010) stated that vitamin D sufficiency was indicated by the

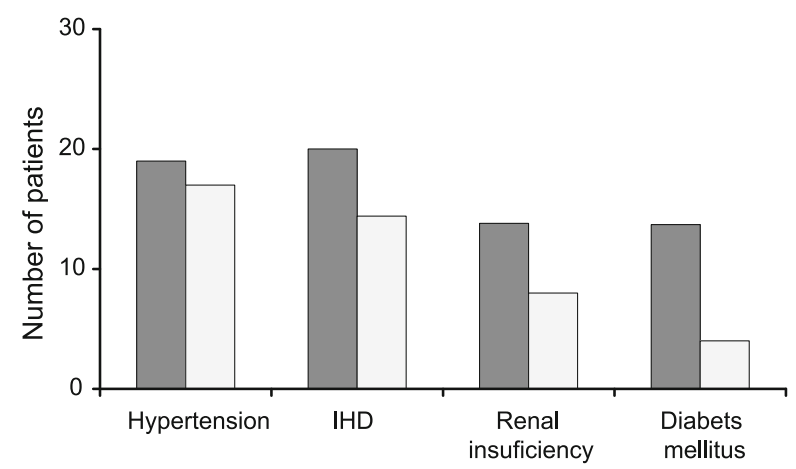

Fig. 4. Distribution of the number of female patients according to diagnoses depending on the vitamin D3 limit value $16 \mathrm{ng} / \mathrm{ml}$. IHD -Ischaemic heart disease, full column - the group related to vitamin D3 < $16 \mathrm{ng} / \mathrm{ml}$, empty column - the group related to vitamin D3 $\geq 16 \mathrm{ng} / \mathrm{ml}$.

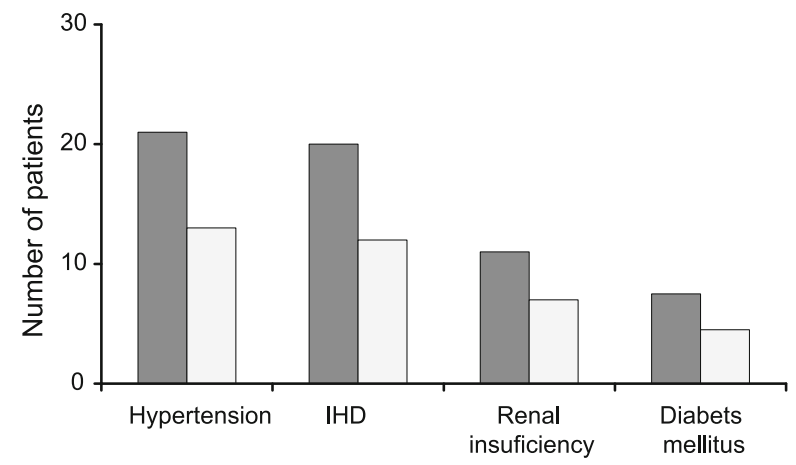

Fig. 5. Distribution of the number of male patients according to diagnoses depending on the vitamin D3 limit value $16 \mathrm{ng} / \mathrm{ml}$. IHD -Ischaemic heart disease, full column - the group related to vitamin D3 $<$ $16 \mathrm{ng} / \mathrm{ml}$, empty column - the group related to vitamin D3 $\geq 16 \mathrm{ng} / \mathrm{ml}$. standard 25(OH)D level of 75-80 nmol/1 (i.e. $30-32 \mathrm{ng} / \mathrm{ml}$ ). Ashraf et al (2009) suggested that the concentration of $15 \mathrm{ng} / \mathrm{ml}$ or less might be the threshold, by which vitamin D3 deficiency conferred negative effects on insulin sensitivity. According to De Boer et al (2012), the threshold concentrations associated with an increased risk for relevant clinical disease was near $20 \mathrm{ng} / \mathrm{ml}$. According to Ginter and Simko (2009), within European countries, serum $25(\mathrm{OH}) \mathrm{D}$ was $<25 \mathrm{nmol} / \mathrm{L}$ in $2-30 \%$ of adults and the deficiency was increasing in elderly people.

The results of our analysis seem to be similar with previous works. The obtained results consider that $16 \mathrm{ng} / \mathrm{ml}$ may present the threshold limit for the risk of diabetes mellitus, hypertension, ischaemic heart disease and renal insufficiency. Urgent research and clinical priorities would be identified, including reassessment of laboratory ranges for $25(\mathrm{OH}) \mathrm{D}$, to avoid problems of both undertreatment and over-treatment (22). Brazdilova et al (2012) detected a negative correlation between obesity and vitamin D3 levels, and a low vitamin D3 concentration in $90 \%$ of 55 tested patients with median $19.36 \mu \mathrm{g} / 1$ (64\% measured in winter, $36 \%$ in summer). They observed no relationship between vitamin D3 levels and season, and a negative correlation between low vitamin D3 concentration and diabetes mellitus. Baykal et al (2012) determined a significantly lower mean serum 25(OH)D levels in the patients with rheumatoid arthritis compared to the healthy subjects. Vitamin D serum levels lower than $20 \mathrm{ng} / \mathrm{ml}$ were observed in $72 \%$ of patients. According to Snellman et al (2010), vitamin D is not only important for bone health, but can also affect the development of several non-bone diseases. The definition of vitamin D insufficiency by serum levels of 25-hydroxyvitamin D depends on the clinical outcome, but might also be a consequence of analytical methods used for the definition. Although numerous 25-hydroxyvitamin D assays are available, their comparability is uncertain. A high inter-assay disagreement was found. The mean 25-hydroxyvitamin D levels were highest for the HPLC-APCI-MS technique ( $85 \mathrm{nmol} / \mathrm{L}, 95 \%$ CI 81-89), intermediate for RIA ( $70 \mathrm{nmol} / \mathrm{L}, 95 \%$ CI 66-74) and lowest with CLIA (60 nmol/L, 95\% CI 56-64). Using the 50-nmol/L cut-off, $8 \%$ of the subjects were insufficient using HPLC-APCI-MS, $22 \%$ with RIA and $43 \%$ by CLIA. The strongest correlation was found for HPLC-APCI-MS $(r=0.7)$, intermediate for RIA $(r=0.5)$ and lowest for CLIA $(r=0.4)$. Regression analyses between the methods revealed a non-uniform variance $(\mathrm{p}<0.0001)$ depending on the level of 25 -hydroxyvitamin $\mathrm{D}$. There were substantial inter-assay differences in performance. The most valid method was HPLC-APCIMS. Calibration between 25-hydroxyvitamin D assays is intricate.

Bolland et al (2014) did a trial sequential meta-analysis of the existing randomized controlled trials of vitamin D supplements, with or without calcium, to investigate the possible effect of the future trials on the current knowledge. He estimated the effects of vitamin D supplementation on myocardial infarction or ischaemic heart disease, stroke or cerebrovascular disease, cancer, total fracture, hip fracture, and mortality in trial sequential analyses using a risk reduction threshold of $5 \%$ for mortality and $15 \%$ for other endpoints.

The effect estimated for vitamin D supplementation with or without calcium for myocardial infarction or ischaemic heart disease (nine trials, 48647 patients), stroke or cerebrovascular disease 
(eight trials 46431 patients), cancer (seven trials, 48167 patients), and total fracture (22 trials, 76497 patients) lays within the futility boundary, indicating that vitamin $\mathrm{D}$ supplementation does not alter the relative risk of any of these endpoints by $15 \%$ or more. Vitamin D supplementation alone did not reduce hip fracture by $15 \%$ or more (12 trials, 27834 patients). Vitamin D co-administered with calcium reduced hip fracture in institutionalized individuals (two trials, 3853 patients), but did not alter the relative risk of hip fracture by $15 \%$ or more in community-dwelling individuals (seven trials, 46237 patients). There is uncertainty whether vitamin $\mathrm{D}$ with or without calcium reduces the risk of death (38 trials, 81 173). These findings suggested that vitamin D supplementation with or without calcium doesnot reduce skeletal or non-skeletal outcomes in unselected community-dwelling individuals by more than $15 \%$.

Long recognized as important for bone health, vitamin D has attracted recent interest for its possible non-skeletal benefits. Many primary care clinicians now include blood tests to measure vitamin D concentrations as part of routine laboratory work and recommend vitamin D supplements, often at high doses, to their patients for the possible prevention of cancer, cardiovascular disease, diabetes, autoimmune disorders, cognitive decline, and other conditions (27).

\section{Conclusion}

The further studies of the relationship between vitamin D3 insufficiency and the presence of hypertension, ischaemic heart disease, renal insufficiency and diabetes mellitus may lead to the new interventions with decrease prevalence of non-skeletal effects of vitamin D3 in humans.

\section{References}

1. Boduroğlu K, Tunçbilek E, Coşkun T, Uçar C. Infantile Galactosialidosis Associated With Vitamin D Deficiency Rickets. Turk J Med Sci 1999; 29: 331-334.

2. Lind L, Wengle B, Lithell H, Ljunghall S. No major metabolic alterations accompany the hypotensive effect of active vitamin D. Ups J Med Sci 1991; 96: 199-204

3. Albertsson D, Gause-Nilsson I, Mellström D, Eggertsen R. Risk group for hip fracture in elderly women identified by primary care questionnaire - clinical implications. Ups J Med Sci 2006; 111: 179-187.

4. Ginter E, Simko V. Vitamin D deficiency, atherosclerosis and cancer. Bratisl Lek Listy 2009; 110 (12): 751-756.

5. Giovannucci E, Liu Y, Hollis BW, Rimm EB. 25-hydroxyvitamin D and risk of myocardial infarction in men: a prospective study. Arch Intern Med 2008; 168: 1174-1180.

6. Pilz S, Marz W, Wellnitz B et al. Association of vitamin D deficiency with heart failure and sudden cardiac death in a large cross-sectional study of patients referred for coronary angiography. J Clin Endocrinol Metab 2008; 93: 3927-3935.

7. Pilz S, Dobnig H, Fischer JE et al. Low vitamin D levels predict stroke in patients referred to coronary angiography. Stroke 2008; 39: 2611-2613.

8. Wang TJ, Pencina MJ, Booth SL et al. Vitamin D deficiency and risk of cardiovascular disease. Circulation 2008; 117: 503-511.
9. Dobnig H, Pilz S, Scharnagl $\mathbf{H}$ et al. Independent association of low serum 25-hydroxyvitamin D and 1,25-dihydroxyvitamin D levels with allcause and cardiovascular mortality. Arch Intern Med 2008; 168: 1340-1349.

10. Holick MF. The vitamin D deficiency pandemic and consequences for nonskeletal health: mechanisms of action. Mol Aspects Med 2008; 29: 361-368.

11. Gillespie KM. Type 1 diabetes: pathogenesis and prevention. CMAJ 2006; 175: 165-170.

12. Hypponen E, Laara E, Reunanen A, Järvelin MR, Virtanen SM. Intake of vitamin $\mathrm{D}$ and risk of type 1 diabetes: a birth-cohort study. Lancet 2001; 358: 1500-1503.

13. Zipitis CS, Akobeng AK. Vitamin D supplementation in early childhood and risk of type 1 diabetes: a systematic review and meta-analysis. Arch Dis Child 2008; 93: 512-517.

14. Agarwal, R. Vitamin D, Proteinuria, Diabetic Nephropathy, and Progression of CKD. Clin J Am Soc Nephrol 2009; 4: 1523-1528.

15. McCartney G, Gordon C, Walsh D, Batty GD. Why the Scots die younger: synthesizing the evidence. Public Health 2012; 126: 459-470.

16. Holick MF. Vitamin D deficiency. N Engl J Med 2007; 357: 266-281.

17. Gordon CM, DePeter KC, Feldman HA, Grace E, Emans SJ. Prevalence of vitamin D deficiency among healthy adolescents. Arch Pediatr Adolesc Med 2004; 158: 531-537.

18. Lips P. Worldwide status of vitamin D nutrition. J Steroid Biochem Mol Biol 2010; 121: 297-300.

19. Schwalfenberg GK, Genuis SJ, Hiltz MN. Addressing vitamin D deficiency in Canada: a public health innovation whose time has come. Public Health 2010; 124: 350-359.

20. Ashraf A, Alvarez J, Saenz K, Gower B, McCormick K, Franklin F. Threshold for effects of vitamin D deficiency on glucose metabolism in obese female African-American adolescents. J Clin Endocrinol Metab 2009; 94: 3200-3206.

21. De Boer IH, Levin G, Robinson-Cohen C et al. Serum 25-Hydroxyvitamin D Concentration and Risk for Major Clinical Disease Events in a Community-Based Population of Older Adults: A Cohort Study. Ann Intern Med 2012; 156: 627-634.

22. Ross AC, Manson JE, Abrams SA et al. The 2011 report on dietary reference intakes for calcium and vitamin D from the Institute of Medicine: what clinicians need to know. J Clin Endocrinol Metab 2011; 96: 53-58.

23. Brazdilova K, Dlesk A, Koller T, Killinger Z, Payer J. Vitamin D deficiency - a possible link between osteoporosis and metabolic syndrome. Bratisl Lek Listy 2012; 113 (7): 412-416.

24. Baykal T, Senel K, Alp F, Erdal A, Ugur M. Is there an association between serum 25-hydroxyvitamin D concentrations and disease activity in rheumatoid arthritis? Bratisl Lek Listy 2012; 113 (10): 610-611.

25. Snellman G, Melhus H, Gedeborg R et al. Determining Vitamin D Status: A Comparison between Commercially Available Assays. PLoS ONE 2010; 5 (7): e11555. doi: 10.1371/journal.pone.0011555.

26. Bolland MJ, Grey A, Gamble GD, Reid IR. The effect of vitamin D supplementation on skeletal, vascular, or cancer outcomes: a trial sequential meta-analysis. Lancet Diabetes Endocrinol 2014; 2 (4): 307-320.

27. Manson JE, Bassuk SS. Vitamin D Research and Clinical Practice at a Crossroads. JAMA 2015; 313 (13): 1311-1312.

Received June 11, 2015. Accepted September 18, 2015. 